\title{
A study of the composition of the Obsoletus complex and genetic diversity of Culicoides obsoletus populations in Spain
}

\author{
Cecilia Aguilar-Vega ${ }^{1 *}$, Belén Rivera ${ }^{1}$, Javier Lucientes ${ }^{2}$, Isabel Gutiérrez-Boada ${ }^{1}$ and \\ José Manuel Sánchez-Vizcaíno’
}

\begin{abstract}
Background: The Culicoides obsoletus species complex (henceforth 'Obsoletus complex') is implicated in the transmission of several arboviruses that can cause severe disease in livestock, such as bluetongue, African horse sickness, epizootic hemorrhagic disease and Schmallenberg disease. Thus, this study aimed to increase our knowledge of the composition and genetic diversity of the Obsoletus complex by partial sequencing of the cytochrome c oxidase I (cox1) gene in poorly studied areas of Spain.
\end{abstract}

Methods: A study of C. obsoletus populations was carried out using a single-tube multiplex polymerase chain reaction (PCR) assay that was designed to differentiate the Obsoletus complex sibling species Culicoides obsoletus and Culicoides scoticus, based on the partial amplification of the cox 1 gene, as well as cox 1 georeferenced sequences from Spain available at GenBank. We sampled 117 insects of the Obsoletus complex from six locations and used a total of 238 sequences of C. obsoletus (ss) individuals (sampled here, and from GenBank) from 14 sites in mainland Spain, the Balearic Islands and the Canary Islands for genetic diversity and phylogenetic analyses.

Results: We identified 90 C. obsoletus (ss), 19 Culicoides scoticus and five Culicoides montanus midges from the six collection sites sampled, and found that the genetic diversity of C. obsoletus (ss) were higher in mainland Spain than in the Canary Islands. The multiplex PCR had limitations in terms of specificity, and no cryptic species within the Obsoletus complex were identified.

Conclusions: Within the Obsoletus complex, C. obsoletus (ss) was the predominant species in the analyzed sites of mainland Spain. Information about the species composition of the Obsoletus complex could be of relevance for future epidemiological studies when specific aspects of the vector competence and capacity of each species have been identified. Our results indicate that the intraspecific divergence is higher in C. obsoletus (ss) northern populations, and demonstrate the isolation of C. obsoletus (ss) populations of the Canary Islands.

Keywords: Obsoletus complex, Cytochrome c oxidase I gene, Culicoides obsoletus, Culicoides scoticus, Culicoides montanus, Bluetongue virus, Single-tube multiplex polymerase chain reaction

\footnotetext{
*Correspondence: ceciagui@ucm.es

${ }^{1}$ Animal Health Department, Faculty of Veterinary Medicine, VISAVET

Health Surveillance Centre, Complutense University of Madrid, Madrid, Spain

Full list of author information is available at the end of the article
}

\section{Background}

Although some species of the genus Culicoides (Diptera: Ceratopogonidae) have been confirmed as biological vectors of numerous arboviruses of veterinary importance, the number of vector species is a very small proportion of the diversity of Culicoides species [1,2]. Three of the

(c) The Author(s) 2021. This article is licensed under a Creative Commons Attribution 4.0 International License, which permits use, sharing, adaptation, distribution and reproduction in any medium or format, as long as you give appropriate credit to the original author(s) and the source, provide a link to the Creative Commons licence, and indicate if changes were made. The images or other third party material in this article are included in the article's Creative Commons licence, unless indicated otherwise in a credit line to the material. If material is not included in the article's Creative Commons licence and your intended use is not permitted by statutory regulation or exceeds the permitted use, you will need to obtain permission directly from the copyright holder. To view a copy of this licence, visit http://creativeco mmons.org/licenses/by/4.0/. The Creative Commons Public Domain Dedication waiver (http://creativecommons.org/publicdomain/ zero/1.0/) applies to the data made available in this article, unless otherwise stated in a credit line to the data. 
arboviruses of the genus Orbivirus (family Reoviridae)-bluetongue virus (BTV), African horse sickness virus (AHSV) and epizootic hemorrhagic disease virus (EHDV) [3] - can have an impact on livestock welfare and cause significant economic losses, and are therefore listed as notifiable diseases by the World Organization for Animal Health [4]. BTV and EHDV affect mainly ruminants, with severe clinical disease observed in sheep and deer, respectively, whilst AHSV infects equids and can cause significant mortality in horses. BTV has been reported in every habitable continent, and since 1998, numerous BTV serotypes have been circulating in Europe [5]. Outbreaks of five BTV serotypes have been reported in Spain since 1956: BTV-10 (1956), BTV-2 (2000), BTV-4 (2003-2005; 2010-2020), BTV-1 (2007-2017; 2020) and BTV-8 (2008-2010; 2020) [6]. AHSV is endemic in subSaharan Africa, but outbreaks have occurred in northern African countries, the Middle East, southwest Asia, and southern regions of Europe [7]. In Spain, two epizootics, with different serotypes, occurred in 1966 (AHSV-9) and 1987-1989 (AHSV-4) [7]. EHDV has been reported in North and South America, Australia, Africa and Asia [8]. Despite not being reported in the European Union, EHDV outbreaks have been declared in Mediterranean Basin countries [9]. This proximity suggests a risk of introduction of EHDV into the EU, as has occurred with AHSV [10] and BTV [10, 11].

Culicoides imicola, a member of the subgenus Avaritia, is deemed the major BTV, AHSV and EHDV vector in Africa, the Middle East, southeast Asia and southern Europe [5, 12]. C. imicola is highly abundant in central and southern regions of mainland Spain [13, 14]. Carpenter et al. [15] showed the vector competence of several Palearctic species of Culicoides prior to the introduction of BTV-8 into northern Europe. After the BTV-8 epizootic in northern Europe, several species of different subgenera were implicated as potential competent BTV vectors in the field: Culicoides chiopterus [16], Culicoides dewulfi, and the Culicoides obsoletus species complex (henceforth 'Obsoletus complex') of the subgenus Avaritia [17]; and the Culicoides pulicaris species complex (henceforth 'Pulicaris complex') [17] of the subgenus Culicoides. In areas of northern European, the Obsoletus complex is considered of great importance in BTV transmission due to its predominance and prevalence in entomological surveys [18], and its vector competence [15, 19, 20]. The Obsoletus complex is widespread in Spain, although it is most abundant in northern regions of the country $[13,14]$. Moreover, $C$. obsoletus breeds in diverse habitats with high organic content, including livestock manure [21-23], and it can breed in indoor locations [24], which implies a great risk of BTV transmission to livestock.
Females of the species that belong to the Obsoletus complex (C. obsoletus and C. scoticus and cryptic species/ clades within the complex) are difficult to distinguish morphologically $[25,26]$. Thus, many studies aimed at assessing oral susceptibility to BTV and EHDV in these sibling species have been performed at the species complex level $[15,20,27]$. Other studies have studied vector competence at species level within the complex, but with a low number of insects $[19,28]$. Those studies proved the susceptibility of the Obsoletus complex to different BTV serotypes [15, 19, 20, 28], and one EHDV serotype [27]. To our knowledge, no study has been carried out on the oral susceptibility of the Obsoletus complex to AHSV, but one study achieved the isolation of AHSV from pools consisting mainly of the Obsoletus and Pulicaris complexes during the 1987-1989 Spanish epizootic [29]. However, sibling species within the complex may have different vector competence and capacities [30].

The mitochondrial DNA (mtDNA) cytochrome $c$ oxidase I $(\operatorname{cox} 1)$ gene is widely used for the molecular identification of species and to study their genetic diversity [31], and is also frequently used to study the diversity of the Obsoletus complex [2, 32-37]. Few studies have yielded Obsoletus complex sequences of cox 1 in Spain [32-34], although a recent study investigated the genetic diversity of the Obsoletus complex at a large scale using insects from 20 different countries, including Spain [35]. The majority of available Spanish cox1 Obsoletus complex sequences have come from Catalonia and the Balearic Islands [33, 35], southeastern areas of Spain [35] and the Canary Islands [32]. The importance of the Obsoletus complex as a biological vector of pathogens that cause severe diseases in livestock [1] justifies the aim of this study to expand our knowledge of the composition and genetic diversity of the Obsoletus complex by using the partial sequencing of the $\operatorname{cox} 1$ gene in poorly studied areas of Spain, as well as to compare our results with georeferenced sequences from Spain that have been deposited in GenBank [38]. Moreover, we developed a multiplex polymerase chain reaction (PCR) to facilitate the differentiation of C. obsoletus from C. scoticus in the region.

\section{Methods}

\section{Specimen collection and identification}

The 117 insects that were analyzed in the current study originate from mainland Spain (they were provided by the Spanish Bluetongue National Surveillance Program), and from a trap that we placed in the Canary Islands (Table 1). Figure 1 shows the location of the collection sites used in this study and those of the georeferenced sequences retrieved from GenBank (Additional file 1: Table S1) [38]. United States Centers for Disease Control 
Table 1 Location of the collection sites of the tested midges of the Culicoides obsoletus species complex (Obsoletus complex)

\begin{tabular}{|c|c|c|c|c|c|c|c|c|c|}
\hline ID & Province & Municipality & Coordinates $^{\mathrm{a}}$ & Date of collection & $\begin{array}{l}\text { No. of midges of } \\
\text { the Obsoletus } \\
\text { complex }\end{array}$ & $\begin{array}{l}\text { No. of } \\
\text { Culicoides } \\
\text { obsoletus }\end{array}$ & $\begin{array}{l}\text { No. of } \\
\text { Culicoides } \\
\text { scoticus }\end{array}$ & $\begin{array}{l}\text { No. of } \\
\text { Culicoides } \\
\text { montanus }\end{array}$ & $\begin{array}{l}\text { No. of } \\
\text { unidentified } \\
\text { Culicoides }\end{array}$ \\
\hline CS & Castellón & Xert & $40.53^{\circ}, 0.13^{\circ}$ & 20 August 2009 & 25 & 22 & 1 & 2 & 0 \\
\hline AS & Asturias & Tineo & $43.34^{\circ},-6.48^{\circ}$ & 13 July 2017 & 14 & 10 & 4 & 0 & 0 \\
\hline AV & Ávila & Candeleda & $40.18^{\circ},-5.28^{\circ}$ & 16 August 2017 & 18 & 18 & 0 & 0 & 0 \\
\hline C & La Coruña & Mabegondo & $43.21^{\circ},-8.29^{\circ}$ & 6 September 2009 & 26 & 22 & 1 & 3 & 0 \\
\hline SE & Seville & Lora del Río & $37.67^{\circ},-5.51^{\circ}$ & 22 May 2007 & 8 & 5 & 0 & 0 & 3 \\
\hline GC1 & Las Palmas & Valleseco & $28.04^{\circ},-15.58^{\circ}$ & $\begin{array}{l}26 \text { September } \\
2018\end{array}$ & 26 & 13 & 13 & 0 & 0 \\
\hline
\end{tabular}

For the geographical location of the study sites, see Fig. 1

ID Identifier

${ }^{\text {a }}$ Coordinates are in decimal degrees and correspond to the centroid of the municipality

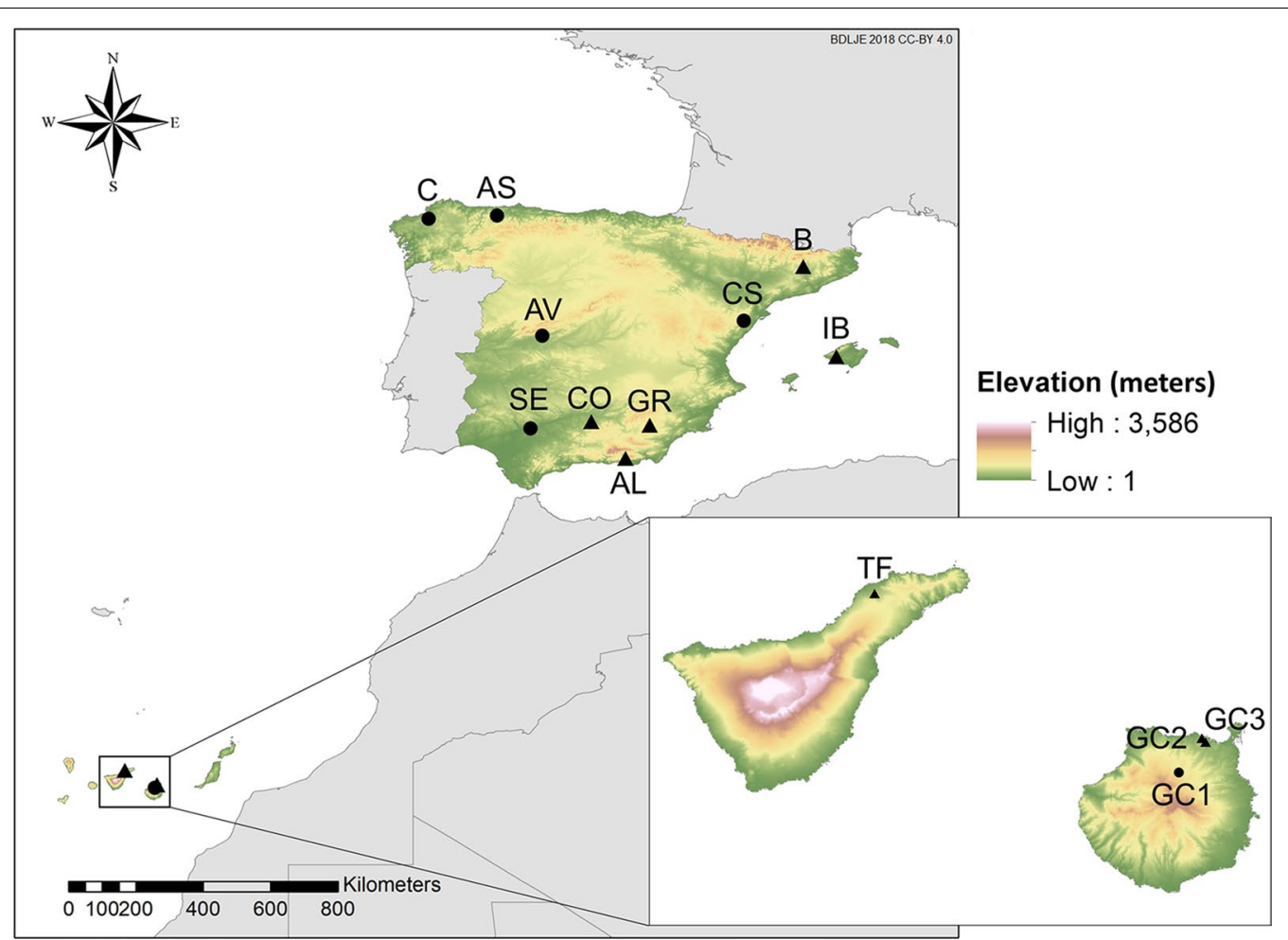

Fig. 1 Location of the collection sites of the midges of the Obsoletus complex used in this study (black dots) and of the georeferenced sequences retrieved from GenBank (black triangles). Elevation of the study area is shown at 15-arc second resolution (GMTED2010 image courtesy of the US Geological Survey [42]). Locations are coded based on the province's location (see Table 1): Barcelona (B), Mallorca (IB), Córdoba (CO), Granada (GR), Almería (AL), Tenerife (TF), Gran Canaria (GC2, GC3). Spanish administrative boundaries were provided by the Instituto Geográfico Nacional (ign.es) (BDDAE CC-BY 4.0)

and Prevention ultraviolet light traps were located in all six collection sites at 1.7- to 2-m height from dusk until dawn close to animal holdings with more than ten susceptible hosts [39]. Insects were preserved in 70\% ethanol prior to identification, and we analyzed females identified as belonging to the Obsoletus complex using different morphological identification keys [40, 41].

\section{DNA extraction and molecular identification}

DNA extraction was performed using the High Pure PCR Template Preparation Kit (Roche Diagnostics, Mannheim, Germany) following the manufacturer's instructions. Specimens had previously been removed from ethanol, dried on absorbent paper, and then homogenized in $100 \mu \mathrm{l}$ of binding buffer. 
For the partial amplification of the mtDNA cox 1 region, we designed two pairs of primers using Primer3Plus v.2.4.2. software [43]. For C. obsoletus (ObL), forward (5'-GGRGTATGAGCCGGAATAAT-3') and reverse (5'-ATTTCGRTCDGTTAARAGYA-3') primers were designed with a product size of $\sim 576$ base pairs (bp). For C. scoticus ( $\mathrm{ScN}$ ), we designed forward (5'-TGC TCCCYCCTTCAATCACT- $3^{\prime}$ ) and reverse ( $5^{\prime}$-ATGCCG GTAGATCGCATATT-3') primers to amplify a shorter sequence ( $\sim 217 \mathrm{bp})$ of the cox 1 region. We checked the sensitivity and specificity of the primer pairs from European $C$. obsoletus and C. scoticus sequences available in GenBank [38] (https://www.ncbi.nlm.nih.gov/genbank/) (Fig. 2). PCR amplification was performed in a $25-\mu \mathrm{l}$ final volume using the following reagents per reaction: $2 \mu \mathrm{l}$ of Nuclease-free water, $15 \mu \mathrm{l}$ of Platinum Green Hot Start PCR 2X Master Mix (Invitrogen, Lithuania), $1.5 \mu \mathrm{l}$ of $20 \mu \mathrm{M}$ forward primers (ObL and ScN), $1.5 \mu \mathrm{l}$ of $20 \mu \mathrm{M}$ reverse primers and $2 \mu \mathrm{l}$ of genomic DNA. The amplification program was as follows: an initial denaturation step at $94{ }^{\circ} \mathrm{C}$ for $5 \mathrm{~min}, 40$ cycles of denaturation at 94 ${ }^{\circ} \mathrm{C}$ for $1 \mathrm{~min}$, annealing for $1 \mathrm{~min}$ and extension at $72^{\circ} \mathrm{C}$ for $1 \mathrm{~min}$, and a final extension step at $72{ }^{\circ} \mathrm{C}$ for $7 \mathrm{~min}$. We optimized the annealing temperature to enhance the specificity to evaluate different annealing temperatures from 54 to $60{ }^{\circ} \mathrm{C}$ in increments of $2{ }^{\circ} \mathrm{C}$. PCR products were stored at $4{ }^{\circ} \mathrm{C}$ until the amplification of the PCR products was confirmed using electrophoresis on $2 \%$ agarose 1xTAE gel that contained SYBR Safe DNA Gel Stain (Invitrogen, USA), with a 100-bp DNA molecular weight marker (Takara). PCR products were purified using QIAquick PCR Purification kit (Qiagen, Germany) in the absence of primer dimer formation. Alternatively, gel bands were purified using QIAquick Gel Extraction kit (Qiagen) and forward strands were externally sequenced by Sanger sequencing using the ObL forward primer. We assigned the Culicoides species level using BLASTN+ 2.10.1 nucleotide [44].

\section{Molecular analysis and phylogenetic tree}

For the molecular analyses and intraspecific sequence polymorphism of C. obsoletus (ss), we included cox1 georeferenced sequences from Spain of $C$. obsoletus, which are available from the GenBank database (https://www. ncbi.nlm.nih.gov/genbank/). DNA polymorphism and haplotype diversity were obtained using DnaSP v.6.12. [45]. A median-joining network for the identified haplotypes was built using Network software v.10.2.0.0 [46], to

\section{KJ162976/C._obsoletus KT186878/C. obsoletus KT186881/C. scoticus MW205919/C._scoticus}

KJ162976/C. obsoletus KT186878/C. obsoletus KT186881/C. scoticus MW205919/C._scoticus

KJ162976/C. obsoletus KT186878/C._obsoletus KT186881/C. scoticus MW205919/C._scoticus

KJ162976/C._obsoletus KT186878/C. obsoletus $\mathrm{KT} 186881 / \mathrm{C}$. scoticus MW205919/C._scoticus
ObL - forward

TTTTTGGAGTATGAGCCGGAATAATTGGTACATCCTTAAGTATACTTATTCGAATAGAAT 60 TTTTTGGGGTATGAGCCGGAATAATCGGAACTTCTTTAAGCATATTAATTCGAACTGAAT 60 TTTTTGGTGTTTGGGCCGGAATAGTGGGAACTTCTCTTAGTATACTAATCCGGGCTGAAT 60 TTTTTGGTGTTTGGGCCGGAATAGTGGGAACTTCTCTTAGTATACTAATCCGGGCTGAAT 60

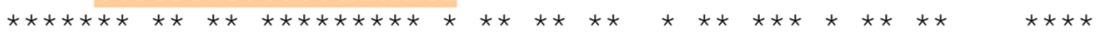

$$
\mathrm{SCN} \text { - forward }
$$

GTTTTTGAATACTACCGCCCTCTATCACCCTACTATTAGTAAGTAGCTTAGTAGAAAATG 300 GATTTTGAATACTCCCACCTTCAATTACTTTATTATTAATTAGAAGCTTAGTAGAAAATG 300 GATTTTGAATGCTCCCTCCTTCAATCACTTTATTATTAATTAGAAGTTTAGTTGAAAATG 300 GATTTTGAATGCTCCCCCCTTCAATCACTTTATTATTAATTAGAAGTTTAGTTGAAAATG 300

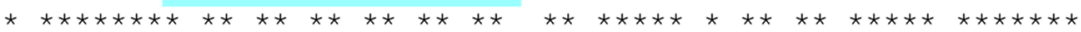

$$
\mathrm{SCN}-\text { reverse }
$$

CTGTAAATTTCATTACCACTATTATTAATATACGTTCTAATGGAATAACTTTTGACCGAA 480 CCGTAAATTTTATTACTACTATTATTAATATACGATCTTACGGGATAACTTTTGACCGAA 480 CAGTAAATTTTATTACCACAATTATTAATATGCGATCTACCGGCATAACTTTTGATCGAA 480 CAGTAAATTTTATTACCACAATTATTAATATGCGATCTACCGGCATAACTTTTGATCGAA 480 $\star * * * * * * * * * * * * * * * * * * * * * * * * * * \quad * * * * * \quad * * * * * * * * * * * * * * * * *$

\section{ObL - reverse}

TATTAGCAGGAGCTATTACGATACTTTTAACAGATCGAAATATTAACACTTCATTTTTTG 600 TTTTAGCAGGAGCTATCACCATGCTCTTAACCGACCGAAATATCAATACTTCATTTTTTG 600 TATTAGCAGGGGCTATTACCATACTTTTAACAGATCGAAATATTAATACTTCATTTTTTG 600 TATTAGCAGGGGCTATTACCATACTTTTAACAGATCGAAATATTAATACTTCATTTTTTG 600 $* * * * * * * * * * * * * * * * * * * * * * * * * * * * * * * * * * * * * * * * * * * * * * * * * *$

Fig. 2 Culicoides obsoletus (ObL) and Culicoides scoticus (SCN) primer location in aligned C. obsoletus and C. scoticus sequences. Only the part of the alignment corresponding with the primer location is shown. Alignment was performed using Clustal Omega software (https://www.ebi.ac.uk/ Tools/msa/clustalo/) 
show the relationships between them. Pairwise genetic differentiation was assessed using the fixation index $\left(F_{\mathrm{ST}}\right)$ calculated in DnaSP [45]. $F_{\mathrm{ST}}$-values can range between 0 and 1 , where 0 shows no differentiation, and 1 no genetic diversity shared between populations [47].

Some cryptic taxa in the Obsoletus complex have been previously identified [35, 48-50]: C. obsoletus O1 [C. obsoletus (ss); MT170705], C. obsoletus O2 (MT173130 and MT172091) and C. obsoletus O3 or clade dark (MT170541 and MT171736). We included representative sequences of each for the construction of our phylogenetic tree, as well as of C. montanus (MT172763), C. scoticus (MT170272) and the closely related C. scoticus clade 2 (MT171305 and MT172198) that is considered to be an intraspecific variant of C. scoticus [35]. We also included Culicoides dewulfi (KT186808 and KJ162977), Culicoides chiopterus (KJ162976 and MW205937), Culicoides imicola (KX641487 and KJ162982) and Culicoides pulicaris (MW207302) sequences.

All phylogenetic analyses were performed in MEGA X [51]. Sequences were aligned using the MUSCLE algorithm [52], and the suitability of the alignment was evaluated through the average evolutionary divergence for all nucleotide sequence pairs ( $p$-distance). To generate a reliable phylogenetic tree, we set the threshold value for the $p$-distance at $<0.8[53,54]$. We inferred a maximum likelihood (ML) phylogenetic tree with the general time reversible model [55] with a gamma distribution and invariant sites, and using 2000 bootstrap replications for reliability. Tree branches with bootstrap values inferior to $50 \%$ were collapsed to form a consensus tree [56].

\section{Results}

\section{cox 1 multiplex PCR optimization}

We evaluated four annealing temperatures in our multiplex cox 1 PCR: 54, 56, 58 and $60{ }^{\circ} \mathrm{C}$. The annealing temperature which improved the specificity was $60{ }^{\circ} \mathrm{C}$ (Fig. 3). For every other temperature, non-specific PCR bands were obtained for $C$. scoticus samples. Hence, the optimal annealing temperature for maximal specificity was $60{ }^{\circ} \mathrm{C}$. However, for poor-quality samples, we found that it might be advisable to decrease the annealing temperature in order to increase sensitivity.

For C. scoticus from the Canary Islands site, ObL primers amplified a $\sim 576$-bp band with an annealing temperature of $54^{\circ} \mathrm{C}$. These bands were purified and sequenced using the $\mathrm{ObL}$ forward primer. Thus, sequences of $C$. scoticus from that location were obtained and included in further analyses. The amplification of some C. scoticus sequences with an annealing temperature of $54^{\circ} \mathrm{C}$ made it necessary to increase the temperature to $60{ }^{\circ} \mathrm{C}$ to be able to correctly differentiate the species and prevent non-specific PCR bands.

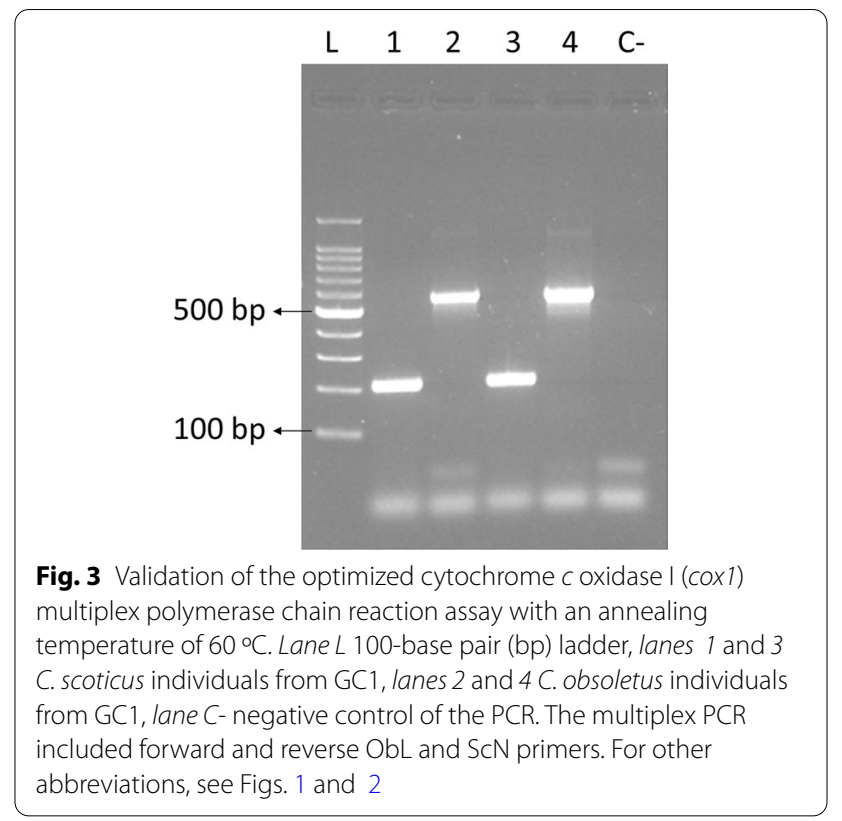

\section{Obsoletus complex sequence diversity for sampled sites}

Of the 117 Obsoletus complex individuals studied here, 90 were identified as C. obsoletus (76.92\%), 19 as C. scoticus (16.24\%) and five as C. montanus (4.27\%); three could not be identified $(2.56 \%)$. The proportion of each species differs greatly in the six sites chosen for the study (Table 1). In SE and AV, all identified insects were $C$. obsoletus, while in GC1 half of the individuals were $C$. scoticus. In AS, CS and C, we identified a total of six $C$. scoticus individuals. C. montanus was identified in CS and $\mathrm{C}$.

We obtained a total of 90 sequences for $C$. obsoletus, 13 for C. scoticus of the Canary Island location, and five for C. montanus. All 108 sequences had a length of $514 \mathrm{bp}$. We found 19 haplotypes for $C$. obsoletus (Ob01-Ob19), three for C. scoticus (Sc01-Sc03) and one for $C$. montanus. Sequences from each haplotype were deposited in GenBank under the following accession numbers: C. obsoletus (MW602810-MW602828), C. scoticus (MW602829-MW602831), and C. montanus (MW602832). The most prevalent C. obsoletus haplotype was Ob13, which was present at all six sampling sites (Fig. 4), and represented $42.22 \%$ (38/90) of all $C$. obsoletus sequences. The Ob13 haplotype was predominant at GC1 (12/13-92.31\%), SE (4/5-80\%) and CS $(11 / 22-42.22 \%)$. Ob10 was found at the four northern locations, while $\mathrm{Ob02}$ and $\mathrm{Ob03}$ were found in $\mathrm{C}$ and AS, Ob05 in AV and CS, and Ob07 and Ob11 in AV and C. Ob08 was only found at C, Ob012 at AV, and Ob04 at AS, but at a relatively high proportion: $5 / 22(22.72 \%)$, $4 / 18(22.22 \%)$ and $3 / 10(30 \%)$, respectively, at each site. 


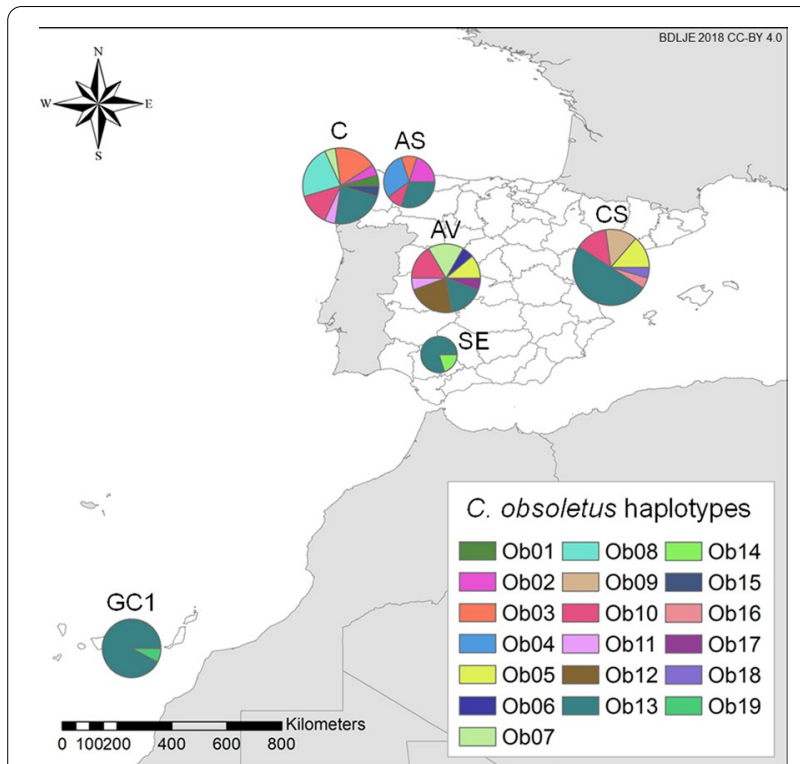

Fig. 4 Distribution of the 19 different C. obsoletus haplotypes identified in this study. Differences in size of the pie charts represent the number of individuals sampled per site. Spanish administrative boundaries were provided by the Instituto Geográfico Nacional (ign. es) (BDDAE CC-BY 4.0). For abbreviations, see Fig. 1

The rest of the haplotypes were only found at one site in low numbers. For the C. scoticus population in the GC1 population, 11/13 individuals belonged to haplotype
Sc03; in contrast, Sc01 and Sc02 haplotypes were are only represented by one individual.

We found that the interspecific nucleotide divergence was greater than the intraspecific diversity, as previously demonstrated $[2,35]$. The total nucleotide diversity for all of the sequences was $0.0307 \pm 0.0053$, while for the $C$. obsoletus (ss) sequences it was $0.0045 \pm 0.0004$, and for C. scoticus $0.0006 \pm 0.0003$. Table 2 shows the sequence polymorphism of C. obsoletus (ss) populations obtained in the present study and from georeferenced sequences retrieved from GenBank.

\section{C. obsoletus sequence diversity compared with external Spanish sequences}

We obtained 148 C. obsoletus (ss) georeferenced sequences from Spain from GenBank (Additional file 1: Table S1), and aligned them with our sequences, which gave a total of 238 sequences. The final length of the alignment was $457 \mathrm{bp}$, and we identified 23 C. obsoletus (ss) haplotypes. Of 148 external sequences, 141 corresponded to one of the haplotypes identified in this study. We maintained the numbering of the identified haplotypes and added consecutive numbers for the new haplotypes identified from the GenBank sequences (Ob20-25). Due to the similarities of the sequences obtained in this study (Additional file 2: Table S2) and their shortening, three pairs of haplotypes had the same sequence in the 457-bp alignment: haplotypes Ob03 and Ob10 (Ob03Ob10), Ob09 and Ob15 (Ob09-Ob15), as well as Sc01

Table 2 Intraspecific polymorphisms of the sequences of C. obsoletus (ss) populations evaluated in this study and of georeferenced sequences retrieved from GenBank

\begin{tabular}{|c|c|c|c|c|c|c|}
\hline$I D^{a}$ & Number of sequences & GC content & $h$ & $\mathrm{Hd}(\mathrm{SD})$ & $S$ & $\pi(\mathrm{SD})$ \\
\hline AL (Genbank) & 6 & 0.339 & 2 & $0.600(0.129)$ & 2 & $0.00263(0.00056)$ \\
\hline AS (this study) & 10 & 0.340 & 4 & $0.822(0.072)$ & 3 & $0.00297(0.00049)$ \\
\hline AV (this study) & 18 & 0.338 & 8 & $0.895(0.038)$ & 7 & $0.00455(0.00064)$ \\
\hline B (Genbank) & 30 & 0.339 & 11 & $0.851(0.046)$ & 10 & $0.00442(0.00048)$ \\
\hline C (this study) & 22 & 0.339 & 8 & $0.823(0.050)$ & 10 & $0.00465(0.00082)$ \\
\hline CO (Genbank) & 13 & 0.339 & 4 & $0.731(0.079)$ & 5 & $0.00424(0.00072)$ \\
\hline CS (this study) & 22 & 0.339 & 6 & $0.723(0.085)$ & 8 & $0.00492(0.00071)$ \\
\hline GC1 (this study) & 13 & 0.339 & 2 & $0.154(0.126)$ & 1 & $0.00034(0.00028)$ \\
\hline GC2 (Genbank) & 37 & 0.339 & 2 & $0.054(0.050)$ & 1 & $0.00012(0.00011)$ \\
\hline GC3 (Genbank) & 11 & 0.339 & 2 & $0.182(0.144)$ & 1 & $0.00040(0.00031)$ \\
\hline GR (Genbank) & 16 & 0.339 & 4 & $0.617(0.096)$ & 5 & $0.00315(0.00068)$ \\
\hline IB (Genbank) & 26 & 0.339 & 4 & $0.625(0.054)$ & 5 & $0.00324(0.00051)$ \\
\hline SE (this study) & 5 & 0.339 & 2 & $0.400(0.237)$ & 3 & $0.00263(0.00156)$ \\
\hline TF (Genbank) & 9 & 0.339 & 1 & - & 0 & - \\
\hline Total & 238 & 0.339 & 23 & $0.690(0.028)$ & 22 & $0.00372(0.00022)$ \\
\hline
\end{tabular}

The analysis was performed using a 457-bp alignment

$h$ Number of haplotypes, $H d$ haplotype (gene) diversity, $S$ number of variable sites, $\pi$ nucleotide diversity (per site)

${ }^{a}$ Identifies the geographical location (see Fig. 1) 


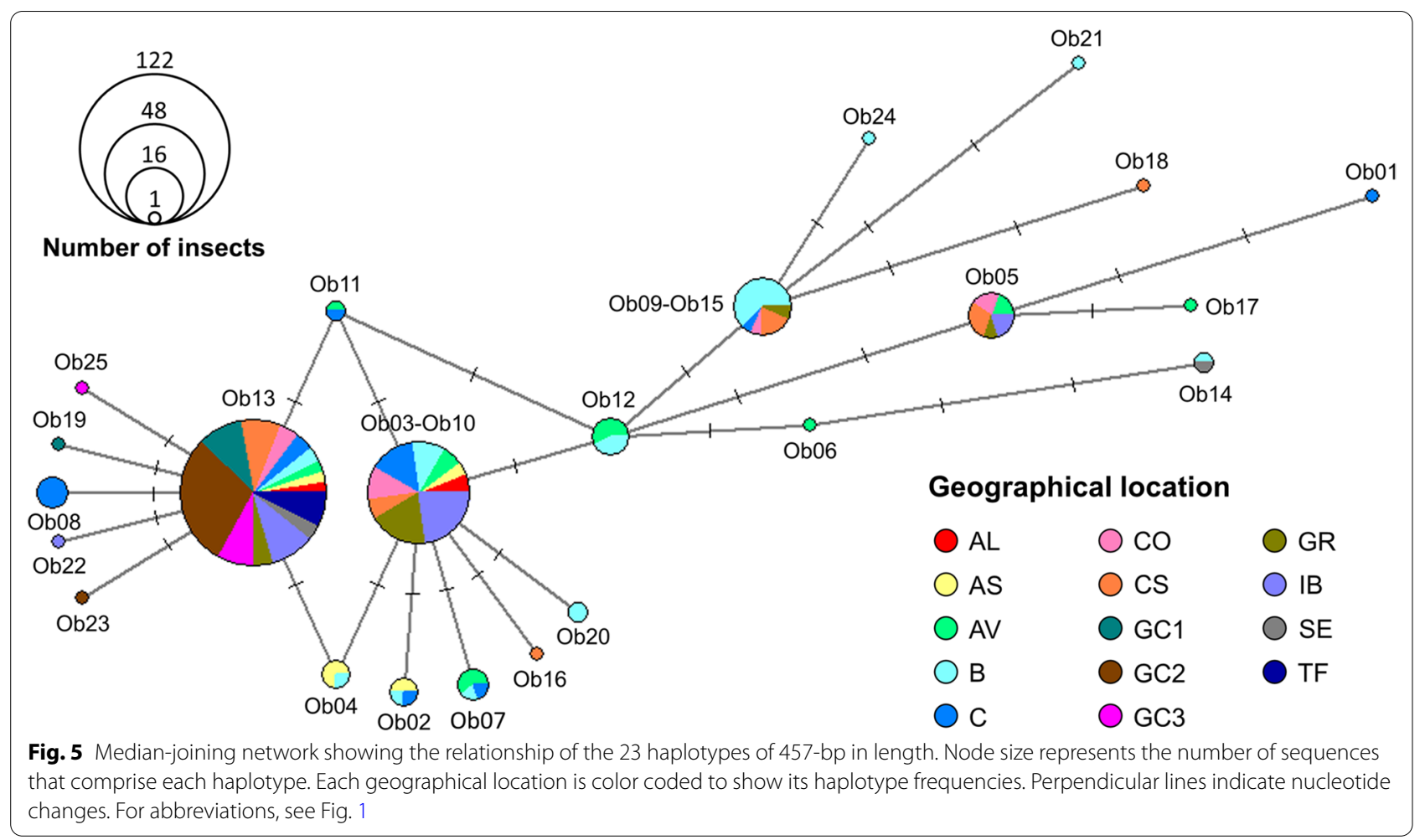

and Sc03 (Sc01-Sc03). Figure 5 shows haplotype relationships determined using a median-joining network. Ob13 was the most frequent haplotype, comprising $51.26 \%(122 / 238)$ of the sequences, and was present at all collection sites. Ob03-Ob10, Ob09-Ob15 and Ob05 also occurred at a relatively high frequency, i.e. in ten or more insects. Eleven haplotypes were from only one individual: six of those identified in our samples and five from GenBank georeferenced sequences.

We found more C. obsoletus (ss) haplotypes and genetic diversity at $\mathrm{B}, \mathrm{C}, \mathrm{AV}, \mathrm{CO}$ and $\mathrm{CS}$ (Table 2). However, SE, $\mathrm{AL}$ and the Canary Islands (GC1-3 and TF) populations had significantly lower intraspecific diversity, although few sequences were included for SE and AL. A pronounced level of genetic differentiation was observed between each Canary Island population, mainland Spain and IB populations in this study with $F_{\mathrm{ST}}$ values $>0.25$, as well as between SE and AS, AV, B and GR (Table 3). Negative $F_{\mathrm{ST}}$ values can be a result of a small sample size in relation to a high number of haplotypes in the population, and should be considered as indicating no genetic differences [57]. Thus, no divergence was found among the Canary Island sites, or with SE, or between some populations on mainland Spain.

\section{Phylogenetic analysis}

The alignment was suitable for the generation of reliable phylogenetic trees, with an average of 0.09 nucleotide substitutions per site when taking into consideration all sequence pairs. The ML phylogenetic tree (Fig. 6) showed that the sequences analyzed here have a small evolutionary distance; this was also supported by the low nucleotide diversity (Additional file 2: Table S2). The tree also corroborates the absence of cryptic species in the area of study.

\section{Discussion}

In the present study, a single-tube multiplex PCR assay based on the partial amplification of the mtDNA cox 1 gene was developed. Previous studies have also developed single-tube multiplex PCR assays for the cox 1 gene for the Obsoletus complex [37, 58, 59]. However, the amplicon size for C. obsoletus used in these assays was inadequate for our posterior sequence diversity and phylogeographic analyses. Our PCR allows the differentiation of C. obsoletus from C. scoticus within the Obsoletus complex, without the need for sequencing derived from the use of generic primer pairs such as $\mathrm{LCO} / \mathrm{HCO}[60]$, C1-J-1718/C1-N-2191 [61, 62], and Lep [63], although ObL primers showed a lack of specificity for the amplification of C. montanus, which we discuss below. We found some cross-reactivity with the ObL primers and $C$. 
Table 3 Genetic differentiation based on pairwise $F_{S T}$ values

\begin{tabular}{|c|c|c|c|c|c|c|c|c|c|c|c|c|c|c|}
\hline$\overline{I D^{a}}$ & $\mathrm{AL}$ & AS & AV & B & C & $\mathrm{CO}$ & CS & GC1 & GC2 & GC3 & $G R$ & IB & SE & TF \\
\hline \multicolumn{15}{|l|}{$A L$} \\
\hline AS & -0.065 & & & & & & & & & & & & & \\
\hline AV & 0.106 & 0.174 & & & & & & & & & & & & \\
\hline B & 0.181 & 0.223 & 0.076 & & & & & & & & & & & \\
\hline C & -0.045 & 0.033 & 0.083 & 0.145 & & & & & & & & & & \\
\hline $\mathrm{CO}$ & -0.045 & 0.045 & -0.004 & 0.08 & -0.008 & & & & & & & & & \\
\hline CS & 0.015 & 0.106 & 0.059 & 0.091 & 0.025 & -0.031 & & & & & & & & \\
\hline GC1 & 0.371 & 0.452 & 0.515 & 0.555 & 0.317 & 0.383 & 0.28 & & & & & & & \\
\hline GC2 & 0.389 & 0.465 & 0.526 & 0.566 & 0.325 & 0.394 & 0.289 & 0 & & & & & & \\
\hline GC3 & 0.367 & 0.447 & 0.511 & 0.552 & 0.314 & 0.379 & 0.278 & 0 & 0 & & & & & \\
\hline GR & -0.057 & 0.027 & 0.033 & 0.103 & 0.01 & -0.045 & 0.041 & 0.513 & 0.53 & 0.509 & & & & \\
\hline IB & -0.089 & 0.02 & 0.095 & 0.183 & -0.005 & -0.031 & 0.014 & 0.356 & 0.371 & 0.352 & -0.003 & & & \\
\hline SE & 0.2 & 0.274 & 0.359 & 0.388 & 0.198 & 0.234 & 0.15 & 0 & 0 & 0 & 0.34 & 0.201 & & \\
\hline TF & 0.4 & 0.479 & 0.532 & 0.573 & 0.332 & 0.401 & 0.294 & 0 & 0 & 0 & 0.539 & 0.379 & 0 & \\
\hline
\end{tabular}

${ }^{a}$ For geographical location, see Fig. 1

scoticus samples at low annealing temperatures, although we designed the primers so as to avoid this. This crossreactivity was overcome by using an annealing temperature of $60{ }^{\circ} \mathrm{C}$ (Fig. 3). Other authors have pointed out similar difficulties concerning the specificity of specifically designed primers for Culicoides species [48]. We did not evaluate whether our primers could amplify other Culicoides species outside the Obsoletus complex, thus previous morphological identification cannot be substituted by our molecular approach. Moreover, morphological identification of all the midges as belonging to the Obsoletus complex coincided with their molecular identification. The correct morphological identification is key to accurately estimate the large-scale distribution of Culicoides species and complex when molecular identification is not achievable.

Primers designed for C. obsoletus (ObL) also amplified one haplotype of $C$. montanus. The existence of other cross-reactions cannot be ruled out for other Obsoletus complex species haplotypes that were not identified in this study for Spain, or for other geographical regions. To overcome the limitations regarding specificity that were encountered for $C$. montanus and some haplotypes of $C$. scoticus at low annealing temperatures of the applied primers, a multi-marker approach including other mitochondrial (cox2 and cytb) and nuclear loci (ITS1 and ITS2) should be considered for future studies in which the main goal is to correctly differentiate between C. obsoletus (ss), C. scoticus, C. montanus and all cryptic species within C. obsoletus [64]. To our knowledge, no PCR for the coxl gene that has been designed enables discrimination of $C$. montanus within the Obsoletus complex/group [37, 48, 58, 59]. Due to the low genetic distance between C. obsoletus (ss) and C. montanus (Fig. 6; Additional file 2: Table S2) [35], it is highly unlikely that specifically generated primers created for $C$. obsoletus (ss) do not also amplify C. montanus, especially if the latter species has not been taken into account in the primer design, as our results show. Some authors have been able to correctly differentiate $C$. montanus from C. obsoletus using the ITS1 [67] and ITS2 markers [66, 68], although other studies faced similar specificity limitations to ours when identifying C. montanus in a PCR designed specifically for $C$. obsoletus that used the ITS2 marker [69].

The prevalence of C. montanus is generally low in entomological surveys, with the exception of some studies carried out in Morocco [35]. Therefore, its role as an arbovirus vector has not yet been defined. In addition, the taxonomic status of $C$. montanus in western Palearctic regions has been questioned by some authors due to the low genetic distance found between it and C. obsoletus (ss) when using different molecular markers $[35,65$, 66].

We found higher genetic diversity in mainland Spain than in the Canary Islands (Table 2). The low genetic diversity, inexistent genetic differentiation among the structure of C. obsoletus (ss) in all Canary Islands populations, and strong divergence with the other sampling sites (Tables 2,3 ) are probably a consequence of their isolation, which implies inbreeding and low gene flow outside the islands [70]. On the other hand, for site IB there was no to low differentiation with mainland Spain, except for site $B$ with which there was moderate divergence, as it had three of the most prevalent haplotypes in this study: Ob03-Ob10, Ob05 and Ob13 (Fig. 5). Its closeness to 


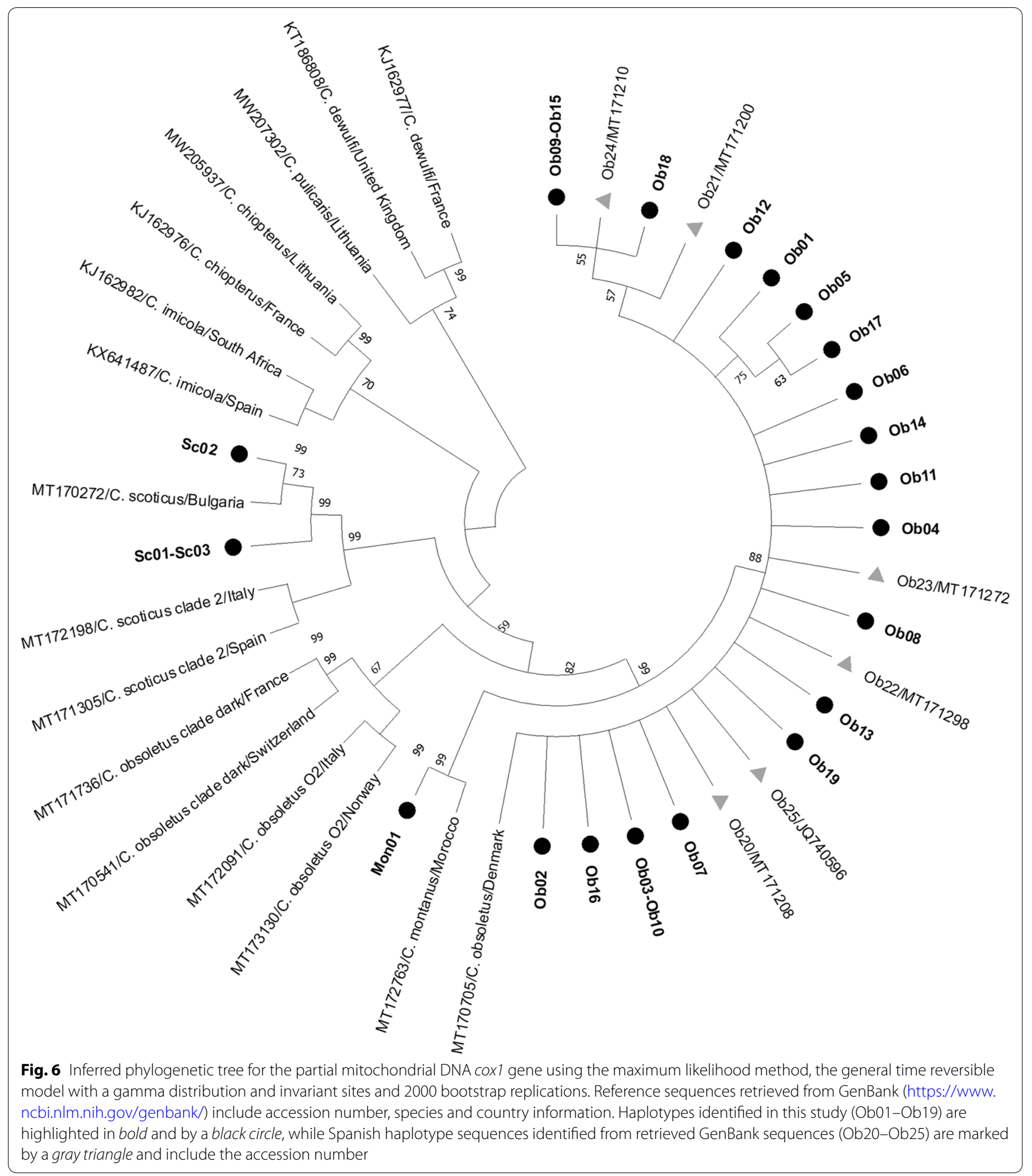

mainland Spain may facilitate gene flow between midge populations of the two. Haplotype and nucleotide diversity in the south of mainland Spain is lower than in northern areas of Spain. These differences can be attributed to sample size; however, the abundance of the Obsoletus complex is higher in northern and mountainous areas of Spain [14], and genetic diversity is partially influenced by population size [70]. In addition to differences in population size, orographic barriers such as altitude (Fig. 1), might limit genetic flow between some of the mainland 
populations in this study, although the limited sample size of some collection sites prevents us from drawing a firm conclusion (Table 3).

We found similar overall proportions of each species to those reported in recently published work [35]. In Mignotte et al. [35], of the 179 sequences analyzed for samples from Spain, 128 (71.51\%) were from C. obsoletus, two from (1.12\%) C. montanus, 28 (15.64\%) from C. scoticus and 21 (11.73\%) from C. scoticus clade 2, although in a site in Catalonia, only C. scoticus midges were identified. Moreover, there are dissimilar ratios for the Canary Islands between our study and that of Mignotte et al. [35], since we identified a 1:1 ratio for C. obsoletus (ss) and C. scoticus, while in the latter study, C. scoticus was not found. The peculiar orographic characteristics of the Canary Islands justify strengthening our knowledge of the Obsoletus complex composition there, in collection sites that are more homogeneously distributed. We did not find C. scoticus clade 2, although we did not obtain a large sequence for any of the six $C$. scoticus midges from mainland Spain. Moreover, we did not find evidence of any cryptic species at any of the sampled sites, as in studies carried out in nearby countries, such as Morocco $[35,71]$. Both C. obsoletus $\mathrm{O} 2$ and C. obsoletus clade dark or O3 have been described from Switzerland, Sweden, Denmark, Finland, Latvia, Norway, France and Italy at latitudes above $45^{\circ}[35,48,50]$. The former has also been described from Poland [35], and C. obsoletus clade dark or O3 from the Netherlands [49]. In the United Kingdom, evidence of Obsoletus complex cryptic taxa has also been found [36]. Cryptic species may have significant epidemiological differences in terms of vector competence, host preferences and breeding sites, although there is as yet no evidence for this [30]. Our results, along with those of previous work carried out on Spanish populations of the Obsoletus complex [33-35], show that C. obsoletus cryptic species $\mathrm{O} 2$ and clade dark might be absent from Spain, present in very low numbers, or present in unsampled locations. The potential absence of cryptic taxa from the Obsoletus complex in Spain may be of relevance to future epidemiological studies, as species-specific vector competence within the complex could be examined by using a greater number of insects $[19,28]$. Nevertheless, more C. obsoletus sequences should also be acquired to definitively exclude the presence of cryptic species in areas with a high abundance of the Obsoletus complex, namely, northern locations [13, 14], which also show more genetic diversity (Table 2).

According to the entomological survey which has been conducted by the Spanish Bluetongue National Surveillance Program since 2004, the Obsoletus complex is the most abundant in northern areas of mainland Spain and the C. imicola complex is generally absent or found in low numbers [14]. Therefore, it is thought that the Obsoletus complex plays a key role in the transmission of BTV there, given that it is a competent vector of the virus [15, 19, 20]. The persistence of BTV in northern Spain was empirically proven by the circulation of BTV-1 from 2007 to 2009 and BTV-8 in 2008 and 2020 [72]. However, the exact contribution of the Obsoletus complex to BTV transmission in central and southern areas of mainland Spain, where C. imicola is the main vector of BTV, has not yet been well defined $[13,73]$.

\section{Conclusions}

Our study reveals that $C$. obsoletus $(s s)$ is the predominant species within the Obsoletus complex in mainland Spain. This information may be of relevance for future epidemiological studies when more robust information is available on specific aspects of the vector capacity (vector competence, adult longevity, biting rate [1]) of each of the sibling species of this complex. Our results show that intraspecific divergence is higher in C. obsoletus (ss) northern populations, and highlight the isolation of $C$. obsoletus (ss) populations in the Canary Islands. No cryptic species within $C$. obsoletus were identified.

\section{Abbreviations}

AHSV: African horse sickness virus; bp: Base pair; BTV: Bluetongue virus; cox1: Cytochrome c oxidase l; EHDV: Epizootic hemorrhagic disease virus; ML: Maximum likelihood; mtDNA: Mitochondrial DNA; PCR: Polymerase chain reaction.

\section{Supplementary Information}

The online version contains supplementary material available at https://doi. org/10.1186/s13071-021-04841-z.

Additional file 1: Table S1. Spanish cox1 georeferenced sequences retrieved from GenBank.

Additional file 2: Table S2. Pairwise distance of the haplotypes identified in this study based on a $p$-distance model.

\section{Acknowledgements}

The authors would like to thank the Spanish Ministry of Agriculture, Fishery and Food for providing data on the Culicoides spp. populations of mainland Spain derived from the Bluetongue National Surveillance Program, and Rocío Sánchez and Débora López (VISAVET) and Rosa Estrada for their exceptional technical assistance in the laboratory.

\section{Authors' contributions}

CAV, BR and JMSV designed the study. JL and IGB provided the necessary samples of Culicoides. CAV performed the DNA extraction and PCRs, and analyzed the obtained data. CAV wrote the first version of the manuscript, which was reviewed and edited by BR, JL, IGB and JMSV. Funding acquisition and project supervision were carried out by JMSV. All authors read and approved the final version of this manuscript.

\section{Funding}

This research was funded by the Horizon 2020 program of the European Union through the Understanding Pathogen, Livestock, Environment Interactions involving Bluetongue project (PALE-Blu; project no 727393-2). CAV is the 
recipient of a Spanish government-funded PhD Fellowship for the Training of Future Scholars awarded by the Spanish Ministry of Science, Innovation and Universities.

\section{Availability of data and materials}

The generated sequences were submitted to the GenBank database under accession nos. MW602810-MW602832.

\section{Declarations}

\section{Ethics approval and consent to participate}

Not applicable.

\section{Consent for publication}

Not applicable.

\section{Competing interests}

The authors declare that they have no competing interests.

\begin{abstract}
Author details
${ }^{1}$ Animal Health Department, Faculty of Veterinary Medicine, VISAVET Health Surveillance Centre, Complutense University of Madrid, Madrid, Spain.

${ }^{2}$ Department of Animal Pathology (Animal Health), Faculty of Veterinary Medicine, AgriFood Institute of Aragón IA2, University of Zaragoza, Zaragoza, Spain.
\end{abstract}

Received: 19 February 2021 Accepted: 11 June 2021

Published online: 03 July 2021

\section{References}

1. Meiswinkel R, Venter GJ, Nevill EM. Vectors: Culicoides spp. In: Coetzer JAW, Tustin RC, editors. Infectious diseases of livestock. 1. Cape Town: Oxford University Press; 2004. pp. 93-136.

2. Garros C, Mathieu B, Balenghien T, Cêtre-Sossah C, Delécolle JC, et al. Suggesting synonymies? Comments on Kiehl et al. (2009) "The European vectors of bluetongue virus: are there species complexes, single species or races in Culicoides obsoletus and C. pulicaris detectable by sequencing ITS-1, ITS-2 and 18S-rDNA"? Parasitol Res. 2009;2010(107):731-4. https:// doi.org/10.1007/s00436-010-1921-z.

3. Walker PJ, Siddell SG, Lefkowitz EJ, Mushegian AR, Dempsey DM, Dutilh $\mathrm{BE}$, et al. Changes to virus taxonomy and the International Code of Virus Classification and Nomenclature ratified by the International Committee on Taxonomy of Viruses. Arch Virol. 2019;164(9):2417-29. https://doi.org/ 10.1007/s00705-019-04306-w.

4. OIE. World Organisation for Animal Health. https://www.oie.int/en/ (2021). Accessed 28 Jan 2021.

5. Wilson AJ, Mellor PS. Bluetongue in Europe: past, present and future. Philos Trans R Soc Lond B Biol Sci. 2009;364:2669-81. https://doi.org/10. 1098/rstb.2009.0091.

6. MAPA. Red de Alerta Sanitaria Veterinaria (RASVE). Madrid: Ministerio de Agricultura, Pesca y Alimentación; 2020.

7. Zientara S, Weyer CT, Lecollinet S. African horse sickness. Rev Sci Tech. 2015;34(2):315-27. https://doi.org/10.20506/rst.34.2.2359.

8. CFSPH. Epizootic hemorrhagic disease. http://www.cfsph.iastate.edu/ Diseaselnfo/factsheets.php (2019). Accessed 07 Sept 2020.

9. Savini G, Afonso A, Mellor P, Aradaib I, Yadin H, Sanaa M, et al. Epizootic heamorragic disease. Res Vet Sci. 2011;91(1):1-17. https://doi.org/10. 1016/j.rvsc.2011.05.004.

10. Durr PA, Graham K, van Klinken RD. Sellers' revisited: a big data reassessment of historical outbreaks of bluetongue and African horse sickness due to the long-distance wind dispersion of Culicoides midges. Front Vet Sci. 2017;4:98. https://doi.org/10.3389/fvets.2017.00098.

11. Burgin LE, Gloster J, Sanders C, Mellor PS, Gubbins S, Carpenter S. Investigating incursions of bluetongue virus using a model of long-distance Culicoides biting midge dispersal. Transbound Emerg Dis. 2013;60(3):26372. https://doi.org/10.1111/j.1865-1682.2012.01345.x.

12. Carpenter S, Mellor PS, Fall AG, Garros C, Venter GJ. African horse sickness virus: history, transmission, and current status. Annu
Rev Entomol. 2017;62(1):343-58. https://doi.org/10.1146/annur ev-ento-031616-035010.

13. Calvete C, Estrada R, Miranda MA, Borrás D, Calvo JH, Lucientes J. Modelling the distributions and spatial coincidence of bluetongue vectors Culicoides imicola and the Culicoides obsoletus group throughout the Iberian peninsula. Med Vet Entomol. 2008;22:124-34. https://doi.org/10. 1111/j.1365-2915.2008.00728.x.

14. Aguilar-Vega C, Fernández-Carrión E, Lucientes J, Sánchez-Vizcaíno JM. A model for the assessment of bluetongue virus serotype 1 persistence in Spain. PLoS ONE. 2020;15(4): e0232534. https://doi.org/10.1371/journal. pone.0232534.

15. Carpenter S, Lunt HL, Arav D, Venter GJ, Mellor PS. Oral susceptibility to bluetongue virus of Culicoides (Diptera: Ceratopogonidae) from the United Kingdom. J Med Entomol. 2006;43(1):73-8. https://doi.org/10. 1093/jmedent/43.1.73.

16. Dijkstra E, van der Ven IJ, Meiswinkel R, Holzel DR, Van Rijn PA, Meiswinkel R. Culicoides chiopterus as a potential vector of bluetongue virus in Europe. Vet Rec. 2008;162(13):422. https://doi.org/10.1136/vr.162.13. 422-a.

17. Meiswinkel R, Baldet T, de Deken R, Takken W, Delécolle JC, Mellor PS. The 2006 outbreak of bluetongue in northern Europe-the entomological perspective. Prev Vet Med. 2008;87:55-63. https://doi.org/10.1016/j.preve tmed.2008.06.005.

18. Mehlhorn H, Walldorf V, Klimpel S, Schmahl G, Al-Quraishy S, Walldorf $U$, et al. Entomological survey on vectors of bluetongue virus in North Rhine-Westfalia (Germany) during 2007 and 2008. Parasitol Res. 2009:105:321-9. https://doi.org/10.1007/s00436-009-1413-1.

19. Carpenter S, McArthur C, Selby R, Ward R, Nolan DV, Mordue Luntz AJ, et al. Experimental infection studies of UK Culicoides species midges with bluetongue virus serotypes 8 and 9. Vet Rec. 2008;163(20):589-92. https://doi.org/10.1136/vr.163.20.589.

20. Federici V, Goffredo M, Mancini G, Quaglia M, Santilli A, Di Nicola F, et al. Vector competence of Italian populations of Culicoides for some bluetongue virus strains responsible for recent northern African and European outbreaks. Viruses. 2019;11(10):941. https://doi.org/10.3390/ v11100941.

21. Harrup LE, Purse BV, Golding N, Mellor PS, Carpenter S. Larval development and emergence sites of farm-associated Culicoides in the United Kingdom. Med Vet Entomol. 2013;27(4):441-9. https://doi.org/10.1111/ mve.12006.

22. González M, López S, Mullens BA, Baldet T, Goldarazena A. A survey of Culicoides developmental sites on a farm in northern Spain, with a brief review of immature habitats of European species. Vet Parasitol. 2013;191:81-93. https://doi.org/10.1016/j.vetpar.2012.08.025.

23. Zimmer JY, Saegerman C, Losson B, Haubruge E. Breeding sites of bluetongue virus vectors, Belgium. Emerg Infect Dis. 2010;16(3):575-6. https:// doi.org/10.3201/eid1603.091311.

24. Ninio C, Augot D, Dufour B, Depaquit J. Emergence of Culicoides obsoletus from indoor and outdoor breeding sites. Vet Parasitol. 2011;183(1):125-9. https://doi.org/10.1016/j.vetpar.2011.07.020.

25. Kluiters G, Pagès N, Carpenter S, Gardès L, Guis H, Baylis M, et al. Morphometric discrimination of two sympatric sibling species in the Palaearctic region, Culicoides obsoletus Meigen and C. scoticus Downes \& Kettle (Diptera: Ceratopogonidae), vectors of bluetongue and Schmallenberg viruses. Parasites Vectors. 2016;9(1):262. https://doi.org/10.1186/ s13071-016-1520-7.

26. Mathieu B, Cêtre-Sossah C, Garros C, Chavernac D, Balenghien T, Carpenter $\mathrm{S}$, et al. Development and validation of IIKC: an interactive identification key for Culicoides (Diptera: Ceratopogonidae) females from the Western Palaearctic region. Parasites Vectors. 2012;5(1):137. https://doi. org/10.1186/1756-3305-5-137.

27. Federici V, Ippoliti C, Goffredo M, Catalani M, Di Provvido A, Santilli A, et al. Epizootic haemorrhagic disease in Italy: vector competence of indigenous Culicoides species and spatial multicriteria evaluation of vulnerability. Vet Ital. 2016;52(3-4):271-9. https://doi.org/10.12834/Vetlt. 894.4516.2.

28. Paslaru Al, Mathis A, Torgerson P, Veronesi E. Vector competence of pre-alpine Culicoides (Diptera: Ceratopogonidae) for bluetongue virus serotypes 1, 4 and 8. Parasites Vectors. 2018;11(1):466. https://doi.org/10. 1186/s13071-018-3050-y. 
29. Mellor PS, Boned J, Hamblin C, Graham S. Isolations of African horse sickness virus from vector insects made during the 1988 epizootic in Spain. Epidemiol Infect. 1990;105(2):447-54. https://doi.org/10.1017/s0950 268800048020.

30. Harrup LE, Bellis GA, Balenghien T, Garros C. Culicoides Latreille (Diptera: Ceratopogonidae) taxonomy: current challenges and future directions. Infect Genet Evol. 2015;30:249-66. https://doi.org/10.1016/j.meegid.2014. 12.018 .

31. Hajibabaei M, Singer GA, Hebert PD, Hickey DA. DNA barcoding: how it complements taxonomy, molecular phylogenetics and population genetics. Trends Genet. 2007;23(4):167-72. https://doi.org/10.1016/j.tig. 2007.02.001.

32. Martínez-de la Puente J, Martínez J, Ferraguti M, Morales-de la Nuez A, Castro N, Figuerola J. Genetic characterization and molecular identification of the bloodmeal sources of the potential bluetongue vector Culicoides obsoletus in the Canary Islands, Spain. Parasites Vectors. 2012;5:147. https://doi.org/10.1186/1756-3305-5-147.

33. Pagès N, Sarto I, Monteys V. Differentiation of Culicoides obsoletus and Culicoides scoticus (Diptera: Ceratopogonidae) based on mitochondrial cytochrome oxidase subunit I. J Med Entomol. 2005;42(6):1026-34. https://doi.org/10.1093/jmedent/42.6.1026.

34. Muñoz-Muñoz F, Talavera S, Carpenter S, Nielsen SA, Werner D, Pagès N. Phenotypic differentiation and phylogenetic signal of wing shape in western European biting midges, Culicoides spp., of the subgenus Avaritia. Med Vet Entomol. 2014;28(3):319-29. https://doi.org/10.1111/mve. 12042.

35. Mignotte A, Garros C, Gardès L, Balenghien T, Duhayon M, Rakotoarivony I, et al. The tree that hides the forest: cryptic diversity and phylogenetic relationships in the Palaearctic vector Obsoletus/Scoticus Complex (Diptera: Ceratopogonidae) at the European level. Parasites Vectors. 2020;13(1):265. https://doi.org/10.1186/s13071-020-04114-1.

36. Barber J, Harrup LE, Silk R, Veronesi E, Gubbins S, Bachanek-Bankowska $K$, et al. Blood-feeding, susceptibility to infection with Schmallenberg virus and phylogenetics of Culicoides (Diptera: Ceratopogonidae) from the United Kingdom. Parasites Vectors. 2018;11(1):116. https://doi.org/10. 1186/s13071-018-2650-x.

37. Nolan DV, Carpenter S, Barber J, Mellor PS, Dallas JF, Mordue AJ, et al. Rapid diagnostic PCR assays for members of the Culicoides obsoletus and Culicoides pulicaris species complexes, implicated vectors of bluetongue virus in Europe. Vet Microbiol. 2007;124(1):82-94. https://doi.org/10. 1016/j.vetmic.2007.03.019.

38. Benson DA, Cavanaugh M, Clark K, Karsch-Mizrachi I, Lipman DJ, Ostell J, et al. GenBank. Nucleic Acids Res. 2016;45:D37-42. https://doi.org/10. 1093/nar/gkw1070.

39. Calvete C, Miranda MA, Estrada R, Borras D, Sarto I, Monteys V, Collantes $\mathrm{F}$, et al. Spatial distribution of Culicoides imicola, the main vector of bluetongue virus, in Spain. Vet Rec. 2006;158:130-1. https://doi.org/10.1136/ vr.158.4.130.

40. Rawlings P. A key, based on wing patterns of biting midges (genus Culicoides Latreille-Diptera: Ceratopogonidae) in the Iberian Peninsula, for use in epidemiological studies. Graellsia. 1996;52:57-71.

41. Delécolle JC. Nouvelle contribution à l'étude systématique et iconographique des espèces du genre Culicoides (Diptéra): (Cératopogonidae) du nord-est de la France. France: Université Louis Pasteur de Strasbourg I; 1985.

42. Danielson JJ, Gesch DB. Global Multi-resolution Terrain Elevation Data 2010 (GMTED2010). US Geological Survey. Open-File Report 2011-1073; 2011. p. 26.

43. Untergasser A, Cutcutache I, Koressaar T, Ye J, Faircloth BC, Remm M, et al. Primer3-new capabilities and interfaces. Nucleic Acids Res. 2012;40(15):e115. https://doi.org/10.1093/nar/gks596.

44. Zhang Z, Schwartz S, Wagner L, Miller W. A greedy algorithm for aligning DNA sequences. J Comput Biol. 2000;7(1-2):203-14. https://doi.org/10. 1089/10665270050081478.

45. Rozas J, Ferrer-Mata A, Sánchez-DelBarrio JC, Guirao-Rico S, Librado P, Ramos-Onsins SE, et al. DnaSP 6: DNA sequence polymorphism analysis of large data sets. Mol Biol Evol. 2017;34(12):3299-302. https://doi.org/10. 1093/molbev/msx248.

46. Fluxus-Engineering. Network version 10.2.0.0, available at: https://www. fluxus-engineering.com/sharenet.htm. 2020.
47. Weir BS, Cockerham CC. Estimating F-statistics for the analysis of population structure. Evolution. 1984;38(6):1358-70. https://doi.org/10.1111/j. 1558-5646.1984.tb05657.x.

48. Wenk CE, Kaufmann C, Schaffner F, Mathis A. Molecular characterization of Swiss Ceratopogonidae (Diptera) and evaluation of real-time PCR assays for the identification of Culicoides biting midges. Vet Parasitol. 2012;184(2-4):258-66. https://doi.org/10.1016/j.vetpar.2011.08.034.

49. Meiswinkel R, De Bree F, Bossers-De Vries R, Elbers AR. An unrecognized species of the Culicoides obsoletus complex feeding on livestock in the Netherlands. Vet Parasitol. 2015;207(3-4):324-8. https://doi.org/10.1016/j. vetpar.2014.12.032.

50. Ander M, Troell K, Chirico J. Barcoding of biting midges in the genus Culicoides: a tool for species determination. Med Vet Entomol. 2013;27(3):323-31. https://doi.org/10.1111/j.1365-2915.2012.01050.x.

51. Kumar S, Stecher G, Li M, Knyaz C, Tamura K. MEGA X: molecular evolutionary genetics analysis across computing platforms. Mol Biol Evol. 2018;35(6):1547-9. https://doi.org/10.1093/molbev/msy096.

52. Edgar RC. MUSCLE: multiple sequence alignment with high accuracy and high throughput. Nucleic Acids Res. 2004;32(5):1792-7. https://doi.org/ 10.1093/nar/gkh340.

53. Thompson JD, Plewniak F, Poch O. A comprehensive comparison of multiple sequence alignment programs. Nucleic Acids Res. 1999;27(13):268290. https://doi.org/10.1093/nar/27.13.2682.

54. Ogden TH, Rosenberg MS. Multiple sequence alignment accuracy and phylogenetic inference. Syst Biol. 2006;55(2):314-28. https://doi.org/10. 1080/10635150500541730.

55. Tavaré S. Some probabilistic and statistical problems on the analysis of DNA sequences. Lectures Math Life Sci. 1986;17:57-86.

56. Hall BG. Phylogenetic trees made easy: a how-to manual. 4th ed. Sunderland, Massachusetts: Sinauer; 2011.

57. Gerlach G, Jueterbock A, Kraemer P, Deppermann J, Harmand P. Calculations of population differentiation based on GST and D: forget GST but not all of statistics! Mol Ecol. 2010;19(18):3845-52. https://doi.org/10. 1111/j.1365-294X.2010.04784.X.

58. Lehmann K, Werner D, Hoffmann B, Kampen H. PCR identification of culicoid biting midges (Diptera, Ceratopogonidae) of the obsoletus complex including putative vectors of bluetongue and Schmallenberg viruses. Parasites Vectors. 2012;5(1):213. https://doi.org/10.1186/1756-3305-5-213.

59. Balczun C, Vorsprach B, Meiser CK, Schaub GA. Changes of the abundance of Culicoides obsoletus s.s. and Culicoides scoticus in Southwest Germany identified by a PCR-based differentiation. Parasitol Res. 2009:105(2):345-9. https://doi.org/10.1007/s00436-009-1412-2.

60. Folmer O, Black M, Hoeh W, Lutz R, Vrijenhoek R. DNA primers for amplification of mitochondrial cytochrome c oxidase subunit I from diverse metazoan invertebrates. Mol Mar Biol Biotechnol. 1994;3(5):294-9.

61. Dallas JF, Cruickshank RH, Linton YM, Nolan DV, Patakakis M, Braverman $Y$, et al. Phylogenetic status and matrilineal structure of the biting midge, Culicoides imicola, in Portugal, Rhodes and Israel. Med Vet Entomol. 2003;17(4):379-87. https://doi.org/10.1111/j.1365-2915.2003.00454.x.

62. Simon C, Frati F, Beckenbach A, Crespi B, Liu H, Flook P. Evolution, weighting, and phylogenetic utility of mitochondrial gene sequences and a compilation of conserved polymerase chain reaction primers. Ann Entomol Soc Am. 1994;87(6):651-701. https://doi.org/10.1093/aesa/87.6. 651.

63. Hajibabaei M, Janzen DH, Burns JM, Hallwachs W, Hebert PD. DNA barcodes distinguish species of tropical Lepidoptera. Proc Natl Acad Sci USA. 2006;103(4):968-71. https://doi.org/10.1073/pnas.0510466103.

64. Mathieu B, Garros C, Balenghien T, Candolfi E, Delécolle JC, Cêtre-Sossah C. A phylogenetic analysis of the biting midges belonging to Culicoides Latreille (Diptera: Ceratopogonidae) subgenus Avaritia using molecular data. Parasites Vectors. 2020;13(1):243. https://doi.org/10.1186/ s13071-020-04111-4

65. Kiehl E, Walldorf V, Klimpel S, Al-Quraishy S, Mehlhorn H. The European vectors of bluetongue virus: are there species complexes, single species or races in Culicoides obsoletus and C. pulicaris detectable by sequencing ITS-1, ITS-2 and 18S-rDNA? Parasitol Res. 2009;105(2):331. https://doi.org/ 10.1007/s00436-009-1414-0.

66. Gomulski LM, Meiswinkel R, Delécolle JC, Goffredo M, Gasperi G. Phylogenetic relationships of the subgenus Avaritia Fox, 1955 including Culicoides obsoletus (Diptera, Ceratopogonidae) in Italy based on 
internal transcribed spacer 2 ribosomal DNA sequences. Syst Entomol. 2005;30(4):619-31. https://doi.org/10.1111/j.1365-3113.2005.00286.x.

67. Mathieu B, Perrin A, Baldet T, Delécolle JC, Albina E, Cêtre-Sossah C. Molecular identification of western European species of obsoletus complex (Diptera: Ceratopogonidae) by an internal transcribed spacer- 1 rDNA multiplex polymerase chain reaction assay. J Med Entomol. 2007;44(6):1019-25. https://doi.org/10.1603/0022-2585(2007)44[1019: miowes]2.0.co; 2 .

68. Monaco F, Benedetto L, Di Marcello V, Lelli R, Goffredo M. Development and preliminary evaluation of a real-time polymerase chain reaction for the identification of Culicoides obsoletus sensu stricto, C. scoticus and C. montanus in the obsoletus complex in Italy. Vet Ital. 2010;46(2):209-14.

69. Mathieu B, Delecolle JC, Garros C, Balenghien T, Setier-Rio ML, Candolfi $\mathrm{E}$, et al. Simultaneous quantification of the relative abundance of species complex members: application to Culicoides obsoletus and Culicoides scoticus (Diptera: Ceratopogonidae), potential vectors of bluetongue virus. Vet Parasitol. 2011;182(2-4):297-306. https://doi.org/10.1016/j. vetpar.2011.05.052.
70. Frankham R. Do island populations have less genetic variation than mainland populations? Heredity (Edinb). 1997;78(Pt 3):311-27. https://doi.org/ 10.1038/hdy.1997.46.

71. Bourquia M, Garros C, Rakotoarivony I, Gardès L, Huber K, Boukhari I, et al. Update of the species checklist of Culicoides Latreille, 1809 biting midges (Diptera: Ceratopogonidae) of Morocco. Parasites Vectors. 2019;12(1):459. https://doi.org/10.1186/s13071-019-3720-4.

72. MAPA. Red de Alerta Sanitaria Veterinaria (RASVE). https://servicio. mapama.gob.es/rasve/ (2021). Accessed 08 Jan 2021.

73. Aguilar-Vega C, Bosch J, Fernández-Carrión E, Lucientes J, SánchezVizcaíno JM. Identifying Spanish areas at more risk of monthly BTV transmission with a basic reproduction number approach. Viruses. 2020;12(10):1158. https://doi.org/10.3390/v12101158.

\section{Publisher's Note}

Springer Nature remains neutral with regard to jurisdictional claims in published maps and institutional affiliations.
Ready to submit your research? Choose BMC and benefit from:

- fast, convenient online submission

- thorough peer review by experienced researchers in your field

- rapid publication on acceptance

- support for research data, including large and complex data types

- gold Open Access which fosters wider collaboration and increased citations

- maximum visibility for your research: over $100 \mathrm{M}$ website views per year

At BMC, research is always in progress.

Learn more biomedcentral.com/submissions 